\title{
The role played by interdependences in ERP implementations: An empirical analysis of critical factors that minimize elapsed time
}

\author{
Lluís Santamaría-Sánchez*, Manuel Núñez-Nickel, Susana Gago-Rodríguez \\ Department of Business Administration, Universidad Carlos III de Madrid, C/Madrid, 126, 28903 Getafe, Madrid, Spain
}

A R T I C L E I N F O

Article history:

Received 15 July 2008

Received in revised form 17 April 2009

Accepted 30 October 2009

Available online xxx

\section{Keywords:}

ERP implementation

Elapsed time

Interdependences

Organizational integration

Facilitator mechanisms

Time savings

Duration models

\begin{abstract}
A B S T R A C T
We analyzed the role played by different module types that influence the time spent on an ERP implementation. By using the concept of interdependences together with organizational integration theory, we distinguished between business-support and value-chain modules and affirmed that their respective implementation times would differ. We also highlighted the existence of time-savings and facilitator mechanisms that could reduce the total elapsed time for an ERP implementation with these module types. We found empirical support for our hypotheses by using data from 141 organizations and using econometric duration models. Through contextual, organizational, and project specific controls, our results lead us to the conclusion that value-chain modules take longer than business-support modules to implement. Furthermore, we found empirical evidence of time-savings and facilitator mechanisms in the ERP implementation process.
\end{abstract}

\section{Introduction}

Understanding the factors influencing ERP implementation time is still a managerial problem. In 2003, the Hackett Group reported time overruns ranging from 24 to 100 percent for IT projects. Focusing on ERP projects, the literature has reported that ERP implementations generally take longer than expected [1]. In particular, 90 percent of ERP projects finish late and, on average, the real time spent on each ERP implementation was four times that estimated originally. Moreover, time overruns resulted in additional costs until completion since the success of the implementation is usually linked to on-time completion [21].

Based on the idea that an ERP implementation could be considered a mechanism for achieving organizational integration across departments, we explored complementary explanations of why some ERP implementations take more time than others. Our work was based on three main arguments:

(1) implementation of value-chain modules (e.g., production or distribution) requires more time than business-support modules (e.g., accounting or human resource management);

(2) characteristics of value-chain modules, particularly their high interdependence, allow time savings during implementation;

\footnotetext{
* Corresponding author. Tel.: +34 91624 8643; fax: +34 916249607 E-mail address: Isantama@emp.uc3m.es (L. Santamaría-Sánchez).
}

(3) business-support modules provide integration mechanisms that facilitate a reduction of the time needed for ERP implementation.

Based on duration models, we obtained empirical support for our theoretical arguments.

We collected data from 141 organizations, for the period 20042006, through personal interviews with managers involved in ERP implementation. This allowed us to focus on the detail of the ERP implementation phases and, thus clearly determine the time to complete the ERP project. In addition to the number and type of modules implemented, we controlled for contextual and organizational factors, as well as for particular ERP project specifics.

\section{Theoretical framework}

2.1. Value-chain versus business-support modules: differences in time implementation

Although the total time spent on an ERP implementation grows with the number of modules used, modules do not require the same time to implement. In particular, value-chain modules (e.g., supplies, production and distribution processes) take more time than business-support modules (e.g., accounting, finance, and human resources management) because of their underlying dependences [2]. 
There are three possible types of interdependences - pooled, sequential, and reciprocal; business-support modules implementations mainly have pooled dependences, whereas valuechain modules are sequentially and reciprocally dependent. Business-support modules impact the whole ERP system but although they are supported by the entire system, their successful implementation does not depend on the completion of other modules. However, the integration of pooled modules must overcome any business misalignment, such as differences between the firm's existing business processes and the ERP module processes that appear during the implementation. Moreover, integrating pooled interdependences requires a narrow interchange of materials, resources, and information [18]. Therefore, business-support module implementations are of relatively low complexity, in terms of the cooperation and communication needed between the different areas of a firm [7]; as a consequence, the implementation time is lower than that for other more complex modules.

On the other hand, the implementation of value-chain modules deals primarily with sequential and reciprocal interdependence. In sequential interdependence, a serial relationship exists between modules: the output of one becomes the input of another. For instance, the marketing plan is an input to the production and purchasing plans. Reciprocal interdependence even more complex: the output of module $A$ is the input for module $B$ and viceversa. Thus, each module is affected by the other. As a result, we conclude that value-chain implementation requires a more coordination and control and that the organizational integration places strong demands on MIS.

In summary, the integration of value-chain modules, takes longer than business-support module implementation. Consequently, our first hypothesis was:

Hypothesis 1. In an ERP system, value-chain modules take longer to implement than business-support modules.

\subsection{Relative time savings in value-chain implementations}

Each value-chain module implementation requires prior coordination of sequential and reciprocal interdependences with other modules in the value chain. Thus the need to verify correct function requires all value-chain modules to be implemented to perform properly in concert with one another. Prototyping and extensive testing are necessary to find and correct configuration errors. This is because value-chain modules do not run in isolation; the majority of organizational areas involved must be coordinated. The implementation of any value-chain module implies a major investment in terms of time of the specific chain but also in the other modules that share its organizational processes. The configuration of common organizational elements among valuechain modules is reused by the rest of the value-chain modules that share part of their business process structure (company code, plants, sales organization, purchasing organization, etc.). So, valuechain modules achieve time benefits since some individual module requirements are repeated in all the modules. Moreover, homogeneity among value-chains reduces ERP implementation time [6].

However, this is not the only reason for time savings in the implementation of value-chain modules. In particular, greater needs for communication, control, and information are accompanied by greater opportunities for learning [19]. In fact, greater coordination effort provides more opportunities for interaction and access to tacit knowledge. It is reasonable to expect that positive returns from knowledge increase in line with shared competencies and skills. Moreover, interactions during the implementation of highly interdependent modules create valuable opportunities to reconsider initial solutions. Experience gained from "small failures" provides feedback [17]; time savings could accrue from mistakes that are avoided in implementing subsequent modules.

By using these arguments (existence of common interrelations and opportunities for learning), we note that the implementation of a module with sequential or reciprocal interrelations helps the implementation of the modules interrelated with it. As a consequence; when a new value-chain module is implemented it seems reasonable to expect a time saving due to value-chain modules already implemented. This expectation leads to our second hypothesis:

Hypothesis 2. The increment of the elapsed time is smaller with each additional value-chain module implemented.

\subsection{Business-support modules as absolute time-savers}

In line with the arguments of our first hypothesis, pooled interdependence confers two interesting characteristics to business-support modules: (1) their capacity to be implemented individually and independently of other types of modules, and (2), the possibility that the time employed in their implementation will be lower than for value-chain modules. Since elapsed time is the important variable to minimize, there should be simultaneous implementation of business-support and value-chain modules. The total elapsed time for a global ERP implementation, rather than being the sum of individual times for all module types is that time spent on the module that takes most time: (value-chain modules in accordance with the Hypothesis 1). In summary, although business-support module implementation also requires time and effort, ignoring other factors, the maximum (or absolute) time employed in the total ERP implementation will coincide with the elapsed time in implementing value-chain modules.

However, business-support modules have another attractive facet: they can provide coordination mechanisms that facilitate the whole ERP implementation by reducing the elapsed time for other kinds of modules (e.g., value-chain) and, as a consequence, the total elapsed time. If the organization chooses the proper coordination mechanisms, the absolute elapsed time required to achieve the ERP implementation will be lower. These mechanisms include tools for standardization, direct supervision, planning, and mutual adjustment.

In a standard organization, business-support units supply coordination mechanisms that enable organizational integration. Accounting units are particular integration mechanisms [16]. They help companies to standardize the inputs, processes, results, and knowledge, from different departments, in order to analyze and compare them by integrating pooled interdependences. Accounting processes formalize plans, and help to integrate sequential interdependence. These processes also support direct supervision and control of the business that allows the coordination of reciprocal interdependences by mutual adaptation, using impersonal coordination modes. Also, budgets are effective in coordinating pooled and sequential interdependences [4].

Human resource management provides methods for standardization, oriented to behavior and output control, especially appropriate for the integration of pooled interdependences. Human resource management is responsible for the direct supervision of inputs, contributing to the integration of reciprocal interdependences by mutual adaptation. Human resource planning is an important organizational mechanism to integrate sequential interdependences [12]. Thus, the human resource area also provides mechanisms to coordinate and integrate pooled, sequential and reciprocal interdependences.

These arguments lead us to postulate that business-support module implementation has a special characteristic that converts 
it into a potential time-saving tool for the whole ERP implementation. Business-support modules deal with people and departments with wide experience in providing coordination mechanisms for diverse organizational processes. In this sense, accounting and human resource modules are not only implemented faster (than value-chain modules), but they also generate added value in terms of time savings, since they offer coordination mechanisms to integrate modules related to activities in the value chain.

In sum, we defend the potentiality of business-support modules for reducing time because they facilitate ERP implementation. These characteristics, together with the organizational units to which they are linked, could explain time reductions in the whole implementation because of the coordination mechanisms that they provide. This does not mean that implementing businesssupport modules gives rise to "negative time"; however, they reduce the global implementation time by accelerating completion of the remaining modules. Thus, without the special features related to business-support modules, an ERP implementation would take more time. Our third hypothesis was:

Hypothesis 3. The implementation of business-support modules contributes to reductions in the total time for an ERP implementation.

Fig. 1shows a graphical representation of our three hypotheses. In prior work, the relationship between the number of modules and the elapsed time was considered linear and positive $[5,14]$. We believed, however, that this relationship would be influenced by the type of modules implemented (value-chain and business-support).

\section{Method}

\subsection{Data collection}

Prior to formulating the interview guidelines, we decided to collect only material related to the same ERP program, SAP, which was the most widely used ERP in the companies; thus avoiding problems in comparing results from different software packages.

In order to collect data, we conducted personal interviews with managers who were involved in ERP implementations. We chose a case method in order to ensure reliability of our data by ensuring that all respondents used similar criteria when responding. The process thus first required us to develop an interview guideline (made up of open-ended questions) derived from the literature and our research goals. From October 2002 to June 2003, we asked the sales force of SAP Spain to review these questions; we also interviewed consultants with wide experience in ERP implementation, managers who had led ERP implementations, and the Board of the Spanish Association of SAP Users (AUSAPE) to review the questions. In July 2003, AUSAPE e-mailed the resultant list of preliminary questions to their members asking for feedback. From July to September 2003, we received replies from some AUSAPE members. We crossed-checked their answers, from e-mail and personal responses, looking for inconsistencies, and then used their comments to improve the quality of questions.

From September 2003 to March 2004, we repeated this process by discussing the revised questions with these contacts and, finally derived a list of 155 open-ended questions that dealt with different issues, including demographic information about the organization and the interviewee. The data involved the modules and characteristics of the SAP program implemented; time taken in the implementation; motivation and problems related with it; and coordination mechanisms for people involved it. In order to avoid confusing interviewees, the questions avoided academic jargon. They defined general topics that stimulate discussion; i.e., the questions were written to avoid directing or limiting answers and the temporal structure of the ERP implementation was discussed in an attempt to establish an objective criterion for the time it should take. We did not want this to be defined by each responder according to their own views, since our concern was to ensure that the differences came from objective data and not from the
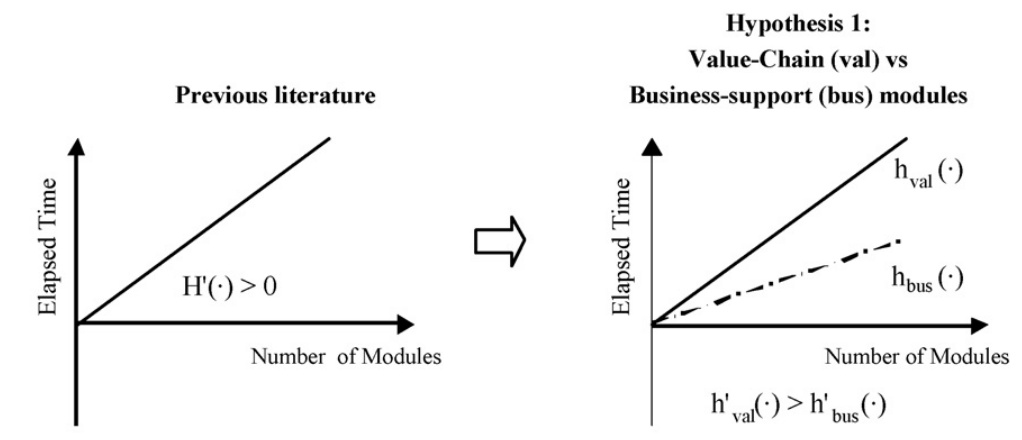

Hypothesis 2:

Relative time savings in

Value-chain implementation

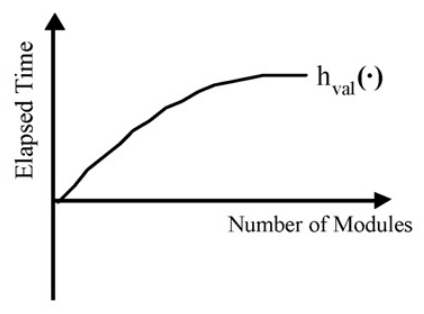

Hypothesis 3:

Business-support modules as

absolute time-savers

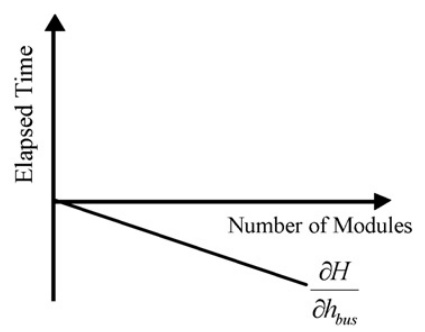

Fig. 1. Graphical development of our hypotheses. 
interviewees' interpretation. Thus, we included detailed questions about the time taken in each of the ERP implementation phases. Moreover, answers from respondents were compared and evaluated using complementary sources of information, such as internal documentation, archival records, and press notes.

The interviews were carried out from March 2004 to June 2006. We visited 141 organizations who had responded with details about their ERP implementation in individual manufacturing sites. We established the first contact with these companies by phone and followed up by informing them of our research interest and our need to interview them personally. However, at no time were the interviewees shown the questionnaire; we used it only as a guide to ensure that we dealt with the same issues during all the interviews.

We interviewed CEOs, senior managers, and project managers. Our interviewees met two requirements: that the company regarded them as the persons most knowledgeable about SAP implementation and that they had participated in the SAP project teams either as manager in charge or key user.

The average length of the interviews was $2.5 \mathrm{~h}$. The interviews were open-ended and oral. In all cases at least two of the authors were present, one concentrating on taking notes while the other conducted the interview. Most of the interviewees did not allow us to use tape recorders, due to the strategic nature of the information. We avoided any tendency to direct answers. To guarantee accuracy, we took written notes and the interviewees examined them and stated their accuracy or highlighted any discrepancy. Occasionally, they would limit the use of the information or hesitate to divulge more due to privacy strictures.

In addition, we used data from internal sources, such as calendars, task lists, budgets, and other internal documents of the implementation team. Finally, we obtained accounting and financial data from the Analysis System of Iberian Balance sheets (SABI), a database from the Bureau Van Dijk Company (Brussels, Belgium).

\subsection{Demographics of the sample}

The demographics of the 141 organizations in our sample are shown in Table 1, which shows a distribution of the respondents by industry. Our sample represents a diverse set of sectors, with almost half devoted to the manufacturing industry. Table 2 provides several characteristics of the organizations (revenues, employees, and headquarters location), together with specific attributes of the ERP projects analyzed.

It is clear that the organizations in our sample are from a wide range of industries, of different sizes in terms of revenue and number of employees, and have their headquarters in a wide range of countries (although Spanish companies are most of our sample). More than half of the organizations spent more than a year in implementing the ERP modules. Moreover, five firms had not finished the implementation at the time of our interview (2006), although we included them in the analysis as censored data. The scope of the modules implemented varied from company to company.

\subsection{Variables}

\subsubsection{Measuring the dependent variable}

In order to represent our dependent variable (elapsed time of the ERP implementation) we needed to specify the time spent, which we chose to be from inception to conclusion; we were also especially careful to define the ERP implementation phases and to avoid subjective interpretations of timescales from our interviewees. Corroborated by internal documents (project plans and
Table 1

Respondents by industry.

\begin{tabular}{|c|c|c|}
\hline Industry & Number & Percentage \\
\hline Air transport & 2 & 1.4 \\
\hline $\begin{array}{l}\text { Business and management consultancy } \\
\text { services }\end{array}$ & 6 & 4.3 \\
\hline $\begin{array}{l}\text { Coke, refined petroleum products and } \\
\text { nuclear fuel }\end{array}$ & 4 & 2.8 \\
\hline Construction & 5 & 3.5 \\
\hline Education & 4 & 2.8 \\
\hline Electricity, gas and water & 7 & 5.0 \\
\hline Finance and Insurance & 9 & 6.4 \\
\hline Food products, beverages and tobacco & 8 & 5.7 \\
\hline Government - regional & 1 & 0.7 \\
\hline Government - state & 1 & 0.7 \\
\hline Health services & 2 & 1.4 \\
\hline Hotels and restaurants & 2 & 1.4 \\
\hline $\begin{array}{l}\text { Information and communications } \\
\text { technology (ICT) services }\end{array}$ & 15 & 10.6 \\
\hline Land transport & 3 & 2.1 \\
\hline Manufacture of basic metals & 1 & 0.7 \\
\hline Manufacture of chemical products & 5 & 3.5 \\
\hline Manufacture of electrical equipment & 8 & 5.7 \\
\hline Manufacture of machinery and equipment & 4 & 2.8 \\
\hline Manufacture of non-metallic mineral products & 4 & 2.8 \\
\hline Manufacture of textiles and textile products & 2 & 1.4 \\
\hline Manufacture of transport equipment & 14 & 9.9 \\
\hline Manufacture of wood and wood products & 2 & 1.4 \\
\hline Office, accounting and computing machinery & 3 & 2.1 \\
\hline Pharmaceuticals & 4 & 2.8 \\
\hline $\begin{array}{l}\text { Publishing, printing and reproduction of } \\
\text { recorded media }\end{array}$ & 9 & 6.4 \\
\hline Radio and television activities & 4 & 2.8 \\
\hline Recreational, cultural and sporting activities & 1 & 0.7 \\
\hline Renting services & 2 & 1.4 \\
\hline Retailing & 7 & 5.0 \\
\hline Travel agencies & 2 & 1.4 \\
\hline Total organizations & 141 & \\
\hline Manufacturing organizations & 70 & 49.7 \\
\hline Service organizations & 55 & 39.0 \\
\hline Distribution organizations & 16 & 11.3 \\
\hline
\end{tabular}

calendars), we identified the Elapsed time spent on the ERP implementation as the difference between inception (the start of the analysis of requirements phase) and completion dates. The start thus dealt with comparing the organizational processes with the procedures in the ERP package; enabling the identification of modules that could be parameterized and those in need of rework. The completion date occurred when all the modules had been tested and installed (the "go live" phase).

\subsubsection{Exogenous variables}

ERP is a configurable system composed of a set of software modules. From the interviews, we were able to identify the number and type of modules implemented. We used Total modules to check the robustness of our empirical model. In order to test our hypotheses, we distinguished between business-support and value-chain modules. Thus the number of business-support modules was related to activities, such as financial accounting, controllers, or human resources management. On the other hand, the number of value-chain modules was linked to activities such as purchasing, production, or sales. To determine potential nonlinear relationships between the endogenous and exogenous variables, we included the squares of Business-support modules and Valuechain modules in our analysis.

In addition to distinguishing between business-support and value-chain modules, we included other modules that do not fit into the activities of previous modules (Other modules). They are multifunctional ones (e.g., Workflow) that facilitate the coordination and interchange of data across the modules. 
Table 2

Sample characteristics.

\begin{tabular}{|c|c|c|c|}
\hline Organizational attribute & Attribute range & Number & Percentage \\
\hline \multicolumn{4}{|c|}{ Firm and project characteristics } \\
\hline \multirow{5}{*}{ Sales } & $<€ 10$ million & 23 & 16.3 \\
\hline & $€ 10-99.99$ million & 43 & 30.5 \\
\hline & $€ 100-499.99$ million & 40 & 28.4 \\
\hline & $€ 500-4999.99$ million & 26 & 18.4 \\
\hline & $>€ 5000$ million & 9 & 6.4 \\
\hline \multirow[t]{5}{*}{ Employees } & $<100$ & 26 & 18.4 \\
\hline & $100-499$ & 29 & 20.6 \\
\hline & 500-999 & 27 & 19.1 \\
\hline & $1000-4999$ & 32 & 22.7 \\
\hline & $>5000$ & 27 & 19.1 \\
\hline \multirow[t]{14}{*}{ Headquarters location } & Belgium & 1 & 0.7 \\
\hline & Finland & 1 & 0.7 \\
\hline & France & 10 & 7.1 \\
\hline & Germany & 12 & 8.5 \\
\hline & Holland & 3 & 2.1 \\
\hline & Italy & 3 & 2.1 \\
\hline & Japan & 3 & 2.1 \\
\hline & Poland & 1 & 0.7 \\
\hline & Portugal & 1 & 0.7 \\
\hline & Sweden & 2 & 1.4 \\
\hline & Switzerland & 3 & 2.1 \\
\hline & United Kingdom & 5 & 3.5 \\
\hline & USA & 15 & 10.6 \\
\hline & SPAIN & 81 & 57.4 \\
\hline Project attribute & Attribute range & Number & Percentage \\
\hline \multicolumn{4}{|l|}{ Modules implemented } \\
\hline \multirow[t]{7}{*}{ Business-support: } & 0 & 2 & 1.4 \\
\hline & 1 & 31 & 22.0 \\
\hline & 2 & 46 & 32.6 \\
\hline & 3 & 34 & 24.1 \\
\hline & 4 & 16 & 11.3 \\
\hline & 5 & 10 & 7.1 \\
\hline & 6 & 2 & 1.4 \\
\hline \multirow[t]{7}{*}{ Value chain: } & 0 & 39 & 27.7 \\
\hline & 1 & 29 & 20.6 \\
\hline & 2 & 37 & 26.2 \\
\hline & 3 & 21 & 14.9 \\
\hline & 4 & 5 & 3.5 \\
\hline & 5 & 9 & 6.4 \\
\hline & 6 & 1 & 0.7 \\
\hline \multirow[t]{7}{*}{ End of ERP implementation } & Before 1995 & 8 & 5.7 \\
\hline & Between 1996-1997 & 8 & 5.7 \\
\hline & Between 1998-1999 & 39 & 27.7 \\
\hline & Between 2000-2001 & 42 & 29.8 \\
\hline & Between 2002-2003 & 28 & 19.9 \\
\hline & Between 2004-2005 & 11 & 7.8 \\
\hline & $\begin{array}{l}\text { Not finished at } \\
\text { the end of data } \\
\text { collection } \\
\text { (June 2006) }\end{array}$ & 5 & 3.5 \\
\hline \multirow[t]{3}{*}{ Elapsed time required } & Less than 1 year & 65 & 46.1 \\
\hline & Between 1 year and 2 & 61 & 43.3 \\
\hline & More than 2 years & 15 & 10.6 \\
\hline
\end{tabular}

\subsubsection{Controlling for other factors in ERP implementations}

The time taken to complete an ERP implementation depends on several factors. We divided them into project-related and contextual or situational ones, associated with sectoral and organizational characteristics.

Along with project-related factors, we distinguished between phased rollout implementations, where the modules are implemented serially, and Big-bang implementations, where the modules are introduced in parallel [13]. Obviously, the decision of which way implement the system will have an impact on the overall elapsed time. In particular, the ERP implementation would take more time if the manager decides to finish the implementation of one module before starting the next (i.e., phased rollout).
We isolated this decision by using a dummy variable (Big-bang implementation) that took on a value of 1 when the firm decided to implement the modules in parallel and zero otherwise.

The specific version of SAP is another project-related control. In particular, we decide to look at the changes in SAP version R/3 4.6. This included new components, functionalities and some features that enhanced the system from a user's viewpoint. Therefore, we assumed that the time needed to implement an earlier version of SAP (e.g., 3.1) would be different from that for more recent versions (e.g., version 4.6). We therefore constructed a dummy variable (New SAPversion), with a value of 1 when the version of SAP was 4.6 or newer or zero otherwise.

The ERP literature provides several critical success factors [9]. One of these is the project team's ability; especially, to access external knowledge [20]. Newly acquired knowledge must be integrated into the decisions and actions of key personnel. This was assumed to increase the probability of timely project completion; thus consultants should prove to be very useful [10]. We controlled for this by using a dummy variable (SAP advisers' involvement) that captured the involvement of SAP advisers and consultants in the implementation process.

Another factor affecting effective project development is user involvement. Traditionally, user involvement was defined as user participation in the systems development process. For an IT project, it provides a better understanding of work processes and information requirements; more realistic user expectations about the system; less resistance to change; and greater led commitment to project success [11]. We control for this effect by using a dummy variable "Employee involvement" which captures the involvement of employees (non-managers) in the implementation process. This variable also allowed us to explore the potential resistance to change by the firm's employees. Several studies have identified this as influential for success of ERP implementations [8].

Organizational size increase has been found to affect bureaucratization, lower flexibility, and slow change. ERP implementation in large companies consequentially tends to be different from that in small or medium-sized companies. In particular, Morabito et al. [15] affirmed that implementing an ERP system required less time in small and medium-sized enterprises (SMEs) than large ones. Therefore, we introduced a "Firm size" variable; we defined it as the logarithm of the firm's assets.

We also controlled for the economic and financial characteristics of the firm. We presumed that wealthy organizations were able to make better decisions about ERP implementation or could manage additional costs that can arise during the implementation process [3]. We included two indicators: "Leverage" measured by the debt-to-equity ratio (total debt divided by total equity) and "Liquidity" measured by the current ratio (current assets divided by current liabilities). We measured these indicators for the year previous to the start of the ERP implementation.

We captured the role of the sector (manufacturing, services, or distribution) of the firm. This was intended to capture the degree of complexity of the firms' value chains. We included two dummy variables ("Manufacture" and "Distribution") to represent the three sectors. They were given a value of 1 if the firm belonged to the manufacturing or distribution sectors and 0 otherwise.

Table 3 contains the descriptive statistics and correlations between all variables used in the study. The Appendix includes descriptions of all variables.

\subsection{The empirical model}

Obviously, our endogenous variable, Elapsed time, only took on positive values with skewness to the left. Thus the normality assumption of OLS regressions did not guarantee consistency of the estimators. The alternative view is survival analysis. Accordingly, 
Table 3

Descriptive statistics and correlations.

\begin{tabular}{|c|c|c|c|c|c|c|c|c|c|c|c|c|c|c|}
\hline & Variable & 1 & 2 & 3 & 4 & 5 & 6 & 7 & 8 & 9 & 10 & 11 & 12 & 13 \\
\hline 1 & Elapsed time & & & & & & & & & & & & & \\
\hline 2 & Business-support modules & 0.52 & & & & & & & & & & & & \\
\hline 3 & Value-chain modules & 0.31 & 0.47 & & & & & & & & & & & \\
\hline 4 & Other modules & 0.09 & 0.36 & 0.39 & & & & & & & & & & \\
\hline 5 & Big-bang implementation & -0.49 & -0.36 & -0.22 & -0.09 & & & & & & & & & \\
\hline 6 & New SAP version & -0.04 & 0.01 & 0.24 & 0.11 & -0.04 & & & & & & & & \\
\hline 7 & Manufacture & 0.24 & 0.34 & -0.04 & 0.06 & -0.05 & -0.02 & & & & & & & \\
\hline 8 & Distribution & 0.02 & -0.06 & 0.09 & 0.06 & -0.11 & 0.01 & -0.30 & & & & & & \\
\hline 10 & Leverage & -0.02 & -0.06 & -0.05 & 0.07 & 0.08 & -0.09 & 0.03 & -0.05 & 0.01 & & & & \\
\hline 11 & Liquidity & -0.05 & -0.01 & -0.11 & -0.05 & -0.13 & -0.10 & -0.09 & -0.04 & -0.09 & -0.32 & & & \\
\hline 12 & SAP advisers' involvement & -0.11 & -0.11 & 0.04 & -0.09 & 0.03 & 0.06 & 0.11 & -0.06 & 0.13 & -0.03 & -0.02 & & \\
\hline \multirow[t]{3}{*}{13} & Employee involvement & 0.17 & 0.12 & -0.01 & 0.12 & 0.12 & -0.05 & 0.17 & -0.02 & -0.14 & 0.09 & 0.05 & -0.03 & - \\
\hline & Mean & 1.06 & 1.73 & 2.52 & 0.19 & 0.69 & 0.59 & 0.46 & 0.09 & 11.77 & 61.51 & 2.58 & 0.04 & 0.83 \\
\hline & Standard deviation & 0.66 & 1.49 & 1.31 & 0.41 & 0.46 & 0.49 & 0.50 & 0.29 & 2.11 & 22.98 & 11.43 & 0.19 & 0.38 \\
\hline
\end{tabular}

Table 4

Comparison of distributions.

\begin{tabular}{lllll}
\hline Distribution & $\begin{array}{l}\text { Number of } \\
\text { parameters } \\
\text { to estimate }\end{array}$ & $\begin{array}{l}\text { Log } \\
\text { likelihood }\end{array}$ & $\begin{array}{l}\text { Akaike's } \\
\text { criterion }\end{array}$ & $\begin{array}{l}\text { Schwarz's } \\
\text { criterion }\end{array}$ \\
\hline Generalized gamma & 3 & -90 & -93 & -97 \\
Weibull & 2 & -90 & -92 & -96 \\
Log-logistic & 2 & -93 & -95 & -98 \\
Log-normal & 2 & -94 & -96 & -99 \\
Gompertz & 2 & -110 & -112 & -115 \\
\hline
\end{tabular}

we used accelerated failure-time (AFT) regression with the expression:

$\ln \left(t_{j}\right)=x_{j} \beta+z_{j}$

where $t_{j}$ is the total time in ERP implementation; $x_{j}$ is the vector of all the exogenous and control variables; $\beta$ is the vector of their respective estimated parameters; and $z_{j}$ is the random error. We chose this model because: (1) it estimates the relationship between elapsed time and the number of modules; and (2), we needed to capture the underlying nonlinear distribution to demonstrate the nonlinear functional relation. In this way, we avoided less intuitive and approximate explanations. The Weibull distribution is the one that best fits our data since it received the

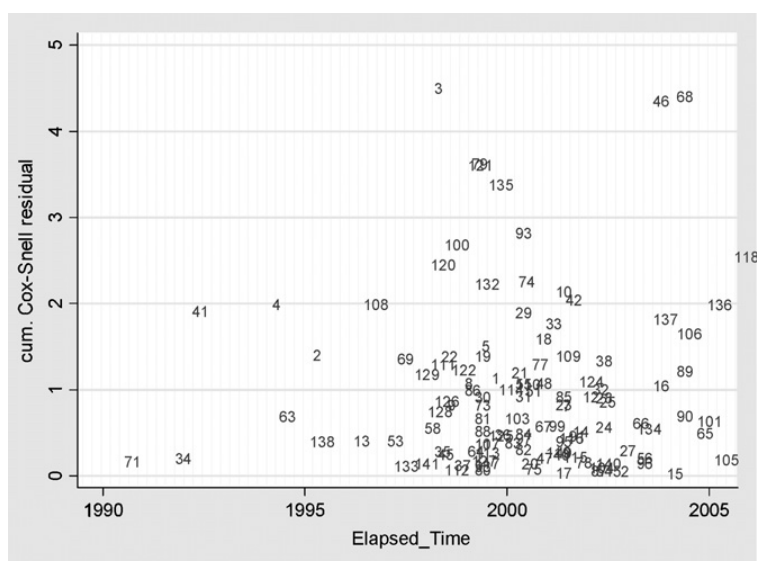

Fig. 2. Cumulative Cox-Snell residuals versus elapsed time. maximum values among the rest of distributions according to Akaike's and Schwarz's criteria (Table 4).

Note that when $\beta$ has a positive and significant sign, the factor or variable of $\beta$ increases the elapsed time. That is, this factor hampers fast implementation. However, when $\beta$ is negative and significant, it reduces the elapsed time, resulting in quick implementation. Finally, when the factor has no significant influence, it does not affect the implementation time.

Given the limited size of the sample, we analyze the influence of outliers by estimating the parameters $\beta$ in our regression model, both for the complete sample $(\beta)$ as well as for the same sample less one " $i$ " observation $\left(\beta^{i}\right)$ each time. Both coefficients were compared using Wald's test. This process was repeated for each of the observations included in the original data. When the equality between parameters could not be accepted at a level of $p<0.05$, we considered the observation as an outlier and it was removed from further analysis. Fig. 2 shows the cumulative Cox-Snell residuals versus our endogenous variable. The 14 outliers can easily be seen since they are above level 2 , in the chart.

We estimated the survival models using the method of pseudomaximum likelihood (STATA 8 software).

\section{Results}

Table 5 displays the results of four models set up to analyze and test our three hypotheses. The first includes control variables only. Model 2 allows us to establish a point of departure from previous research with, a positive relationship between the total number of modules in a project and the elapsed time. The two remaining models demonstrate whether or not our hypotheses are supported. Hence, Hypothesis 1 would be valid if the slopes for Value-chain modules in Model 3 were significantly positive and larger than for Business-support modules. We would have support for Hypothesis 2 if the elapsed time function with respect to the number of valuechain modules is concave, or if the coefficient of the variable without transformation (Value-chain modules) was significant and positive and the coefficient of the same variable, but with the square transformation, was significant and negative. Hypothesis 3 would be supported if the relationship between elapsed time and the number of business-support modules was significant and negative.

Model 3 shows strong and robust support for Hypothesis 1; the impact of the number of value-chain modules on the elapsed time for ERP implementations was positive and significant $(p<0.002)$. On the other hand, the influence of business-support modules was not significant and thus we cannot conclude that this coefficient 
Table 5

Weibull regression results.

\begin{tabular}{|c|c|c|c|c|}
\hline Independent variables & Model 1 & Model 2 & Model 3 & Model 4 \\
\hline Total modules & & $0.0586^{* * *}(0.014)$ & & \\
\hline Value-chain modules & & & $0.098^{* * *}(0.032)$ & $0.205^{* * *}(0.06)$ \\
\hline (Value-chain modules) $^{2}$ & & & & $-0.023^{* *}(0.01)$ \\
\hline (Business-support modules) $^{2}$ & & & & $0.041^{* * *}(0.015)$ \\
\hline Other modules & & & $-0.110(0.074)$ & $-0.117^{*}(0.07)$ \\
\hline Big-bang implementation & $-0.582^{* * *}(0.100)$ & $-0.435^{* * *}(0.09)$ & $-0.413^{* s *}(0.092)$ & $-0.387^{* * *}(0.086)$ \\
\hline New SAP version & $-0.023(0.076)$ & $-0.069(0.072)$ & $-0.065(0.072)$ & $-0.018(0.075)$ \\
\hline Distribution & $0.062(0.12)$ & $0.102(0.121)$ & $0.113(0.12)$ & $0.139(0.122)$ \\
\hline Firm size & $0.053^{* * * *}(0.017)$ & $0.0530^{* * *}(0.016)$ & $0.046^{* * * *}(0.02)$ & $0.048^{* *}(0.02)$ \\
\hline Leverage & $0.001(0.00)$ & $0.003(0.001)$ & $0.002(0.001)$ & $0.002(0.001)$ \\
\hline Liquidity & $-0.0045^{* * *}(0.001)$ & $-0.0026^{* *}(0.001)$ & $-0.0032^{* *}(0.001)$ & $-0.004^{* * *}(0.001)$ \\
\hline SAP advisers' involvement & $-0.365^{*}(0.205)$ & $-0.380^{* *}(0.159)$ & $-0.371^{* *}(0.153)$ & $-0.457^{* * *}(0.142)$ \\
\hline Employee involvement & $0.35^{* * *}(0.082)$ & $0.303^{* * *}(0.075)$ & $0.316^{* s *}(0.071)$ & $0.287^{* * *}(0.072)$ \\
\hline Constant & $-0.530^{* *}(0.266)$ & $-0.902^{* * *}(0.266)$ & $-0.827^{* * *}(0.266)$ & $-0.638^{* *}(0.306)$ \\
\hline Log likelihood & -68.5524 & -61.5359 & -59.8030 & -56.61 \\
\hline Global $\chi^{2}$ test & $90.7^{* * *}$ & $86.7^{* * *}$ & $98.5^{* * *}$ & 104. $7^{* * *}$ \\
\hline
\end{tabular}

Estimates from Weibull regressions are shown. Standard errors are in parentheses.

${ }^{*} p<0.10$.

*** $p<0.05$

$p<0.01$

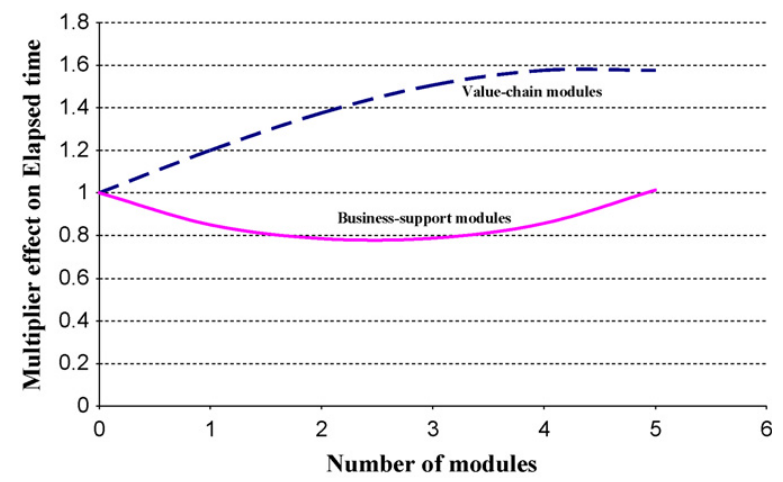

Fig. 3. Multiplier effect of total number of modules on elapsed time.

was different from zero. However, we can add more precision to the latter result, since the lack of significance in Model 3 is the consequence of a clear convex, although always negative, relationship between the implementation of business-support modules and the delay in ERP implementation. In Model 4, the coefficients estimated are negative, with $p<0.029$ for Business-support modules and positive with $p<0.007$ for its square transformation. Thus, we have support for Hypothesis 3. Similarly, Model 4 shows a positive coefficient with $p<0.002$ for Value-chain modules, and significantly negative value $(p<0.065)$ for its square transformation. In conclusion, we also had support for Hypothesis 2. Fig. 3 exhibits the curvilinear relationships graphically. The goal was to compare the empirical results with our theoretical reasoning.

We see, in Table 5, that the sign, the magnitude, and the significance level of the coefficients were stable throughout the different models, independent of the exogenous variables included in the models.

In relation to the characteristics of the project, Big-bang implementation is always highly significant with a negative effect on the implementation time. That is, when the modules were implemented in parallel the time spent was shorter, when compared with contexts where the modules are implemented serially. We did not observe any significant impact of the ERP version on the elapsed time.
Two contextual factors had a significant impact on elapsed time: Firm Size and Manufacture. Firm Size could be a synonym for complexity and thus it was negatively related to the probability of a fast implementation. In the same way, the Manufacturing sector had results that were always positive and highly significant. It seems reasonable to think that firms in the manufacturing sector would have more complex value chains, than other sectors. Consequently, manufacturing sector ERP implementation time will always be longer.

From our data, Liquidity was always significant; the availability of cash at the beginning of the implementation contributed to higher implementation speed. On the other hand, Leverage was not significant in any of the models.

With regard to project-related factors, SAP advisers were found to be needed in the implementation process since they tap knowledge from both the vendor and consultants, thereby reducing the implementation time.

\section{Discussion and conclusions}

The purpose of our study was to investigate the influence of the type of ERP modules used on the time required to achieve organizational integration via ERP implementation. Past research has suggested that the greater the number of modules, the longer the elapsed time. However, the effects on the ERP implementation vary considerably from module to module. Our aim was to explore this.

The significance of our results leads us to three conclusions.

1. As Barki and Pinsonneault stated, the integration of valuechain modules requires more time than business-support modules.

2. The concave relationship between elapsed time and the implementation of value-chain modules is proof of the presence of time savings during the integration of value-chains.

3. Business-support units act as facilitators for ERP implementation. However, their contribution to a reduction in elapsed time decreases as the number of business-support modules exceeds a threshold.

We demonstrated that higher complexity and size of ERP implementations has a greater effect on time. However, different factors affect this result. In particular, not all types of modules 


\section{Endogenous variable}

Elapsed time

Exogenous variables

Total modules

Business-support modules

Value-chain modules

Other modules

Control variables

Big-bang implementation

New SAP version

SAP advisers involvement

Employees involvement

Firm size

Leverage

Liquidity

Manufacture

Distribution
This measures the period of time between the beginning (requirements analysis and specification) and the completion ("Go live") phase of the ERP implementation

Number of implemented modules

Number of Business-support modules (Financial Accounting, Controlling, Human Resources, etc.)

Number of Value-chain modules (Purchasing, Production, Sales, etc.)

Other modules implemented (such as Workflow or Business warehouse)

Dummy variable. Value $=1$ when firm decided to implement the modules in parallel (big-bang), and 0 when serial (phased roll out) Dummy variable. Value $=1$ when version of SAP was the 4.6 or newest, and 0 otherwise Dummy variable. Value $=1$ if SAP advisers/consultants were involved and 0 otherwise

Dummy variable. Value $=1$ if Employees were involved in the implementation and 0 otherwise

Natural logarithm of the assets of the company

Debt-to-equity ratio. Total debt divided by total equity

Current ratio. Current assets divided by current liabilities

Dummy variable. Value $=1$ if firm belongs to the manufacturing sector and 0 otherwise

Dummy variable. Value $=1$ if firm belongs to distribution sector; 0 otherwise require the same implementation time. The inverse U-shape of the value-chain modules curve suggested that there were time savings during the implementation process. Moreover, complex interdependences in value-chain units, while creating the need for communication, control, and information coordination, also provide learning opportunities.

Previous results confirmed that companies lose time-saving opportunities by not incorporating their know-how when integrating business-support units. Value-chain modules should accrue specific benefits as a result of being implemented jointly with business-support modules. The potential for a reduction in elapsed time from the linking of value-chain modules can lead to reductions in the time taken in ERP implementation.

Our study was not, of course, exempt from limitations. The main shortcoming was its generalizability. However, our observations were collected from a broad range of organizations, industries, and ERP projects. Also, though the firms were located in Spain, the presence of multinational firms from a wide range of countries compensated for this weakness. Finally, though our results shed light on the ERP implementation process, we obtained evidence consistent with previous studies. Therefore, it would seem reasonable to regard our sample as representative of a wide population of ERP implementers.

Our results might suffer from a bias due to its concentration on a Latin culture or Mediterranean economy; studies in one country may not apply in other countries. However, the majority of the sample firms have transnational cultures and values, because they have been developing their business in a Western economy as part of the European Union for decades.

Although we included a relatively wide range of control variables, alternative variables could affect the analysis. In particular, the inclusion of variables, such as institutional or corporate governance elements, could increase the richness of the analysis.

\section{Acknowledgements}

We are grateful to Edgar $\mathrm{H}$. Sibley (editor) and three anonymous referees for valuable comments and insights. This research received financial support from the Spanish Education and Science Ministry Projects: SEJ2004-08176 and SEJ2007-67582.

\section{Appendix A}

See Table A1.

\section{References}

[1] D. Aloini, R. Dulmin, V Mininno, Risk management in ERP project introduction: review of the literature, Information \& Management 44, 2007, pp. 547-567.

[2] H. Barki, A. Pinsonneault, A model of organizational integration, implementation effort, and performance, Organization Science 16 (2), 2005, pp. 165-179.

[3] M. Bradford, J. Florin, Examining the role of innovation diffusion factors on the implementation success of enterprise resource planning systems, International Journal of Accounting Information Systems 4 (3), 2003, pp. 205-225.

[4] R.H. Chenhall, Management control systems design within its organizationa context: findings from contingency-based research and directions for the future accounting, Organizations and Society 28 (2-3), 2003, pp. 127-168.

[5] C. Francalanci, Predicting the implementation effort of ERP projects: empirical evidence on SAP/R3, Journal of Information Technology 16 (1), 2001, pp. 33-48.

[6] T.F. Gattiker, D.L. Goodhue, Understanding the local-level costs and benefits of ERP through organizational information processing theory, Information \& Management 41, 2004, pp. 431-443.

[7] D.E. Harter, S.A. Slaughter, Quality improvement and infrastructure activity costs in software development: a longitudinal analysis, Management Science 49 (6), 2003, pp. 784-800.

[8] K.K. Hong, Y.G. Kim, The critical success factors for ERP implementation: an organizational fit perspective, Information \& Management 40 (1), 2002, pp. 2540.

[9] S.-J. Huang, W.-M. Han, Exploring the relationship between software project duration and risk exposure, Information \& Management 45, 2008, pp. 175 182.

[10] D.-G. Ko, L.J. Kirsch, W.R. King, Antecedents of knowledge transfer from consultants to clients in enterprise system implementations, MIS Quarterly 29 (1) 2005, pp. 59-85.

[11] K.-Y. Kwahk, J.-N. Lee, The role of readiness for change in ERP implementation: theoretical bases and empirical validation, Information \& Management 45, 2008 pp. 474-481.

[12] C.A. Lengnick-Hall, M.L. Lengnick-Hall, Strategic human resources management: a review of the literature and a proposed typology, Academy of Management Review 13 (3), 1988 July, pp. 454-470.

[13] M. Markus, S. Axline, D. Petrie, C. Tanis, Learning from adopters' experiences with ERP: problems encountered and success achieved, Journal of Information Technology 15 (4), 2000, pp. 245-265.

[14] V. Mitchell, Knowledge integration and information technology project performance, MIS Quarterly 30 (4), 2006, pp. 919-939.

[15] V. Morabito, S. Pace, P. Previtali, ERP marketing and Italian SMEs, European Management Journal 23 (5), 2005, pp. 590-598.

[16] J. Mouritsen, S. Thrane, Accounting, network complementarities and the development of inter-organizational relations, accounting, Organizations and Society 31 (3), 2006, pp. 241-275 
[17] J.E. Scott, I. Vessey, Implementing enterprise resource planning systems: the role of learning from failure, Information Systems Frontiers 2 (2), 2000, pp. 213-232.

[18] R. Sharma, P. Yetton, The contingent effects of management support and task interdependence on successful information systems implementation, MIS Quarterly 27 (4), 2003, pp. 533-555.

[19] M. Sobrero, E.B. Roberts, The trade-off between efficiency and learning in interorganizational relationships for product development, Management Science 47 (4), 2001, pp. 493-511.

[20] Q. Xu, Q. Ma, Determinants of ERP implementation knowledge transfer, Information \& Management 45, 2008, pp. 528-539.

[21] Z Zhang. M. Lee, P. Huang L. Zhang X. Huang, A framework of ERP systems implementation success in China: an empirical study, International Journal of Production Economics 98 (1), 2005, pp. 56-80.

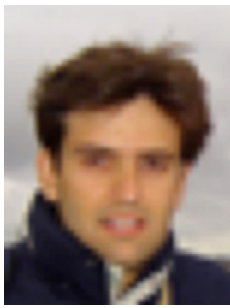

Lluís Santamaría-Sánchez is an assistant professor at the Department of Business Administration, Universidad Carlos III de Madrid, Spain. He holds a Ph.D. in business administration and a Licentiate degree in business and economics from Autonomous University of Barcelona, Spain. His current research focuses on information systems, management of innovation and technological agreements. His research articles have been published in such Journals as Research Policy, Technovation, RED Management, Journal of Small Business Management, Technology Analysis \& Strategic Management, and others.

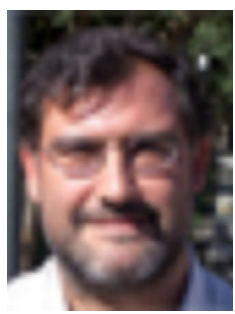

Manuel Núñez-Nickel is the professor of accounting at the Department of Business Administration, Universidad Carlos III de Madrid, Spain. He holds a Ph.D. in economics from Carlos III University and a Licentiate degree in Business and Economics from Complutense University in Madrid (Spain). His research interests center on the influence of strategic-institutional factors on voluntary disclosure. His research articles have been published in such Journals as Administrative Science Quarterly, Academy of Management Journal, Journal of Management Studies, Organization Studies, Omega, Small Business Economics, and others.

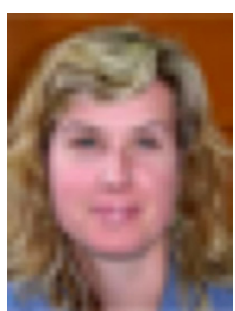

Susana Gago-Rodríguez is an associate professor of Accounting at the Department of Business Administration, Universidad Carlos III de Madrid, Spain. She holds a $\mathrm{Ph} . \mathrm{D}$. in business administration and a Licentiate degree in business and economics from University of Santiago de Compostela, Spain. Her research interests center on ethics, individuals and accounting information systems. She has published in journals, such as Journal of Business Ethics, Accounting Forum, Critical Perspectives on Accounting, and others. 